\title{
UTILIZAÇÃO DA FARINHA DE BABAÇU COMO EXTENSOR ALTERNATIVO NA PRODUÇÃO DE PAINÉIS COMPENSADOS
}

\author{
USE OF BABAÇU FLOUR AS ALTERNATIVE EXTENDER FOR PLYWOOD MANUFACTURING
}

\author{
Érika da Silva Ferreira $^{1}$ Edvá Oliveira Brito ${ }^{2}$ Setsuo Iwakiri $^{3} \quad$ Silviana Rosso $^{4}$ Djeison Cesar Batista ${ }^{5}$
}

\section{RESUMO}

O objetivo desta pesquisa foi avaliar a potencialidade de uso da farinha de babaçu sob diferentes percentuais $(0,50,75$ e 100\%) como extensor alternativo à farinha de trigo para produção de painéis compensados. Foram produzidos 32 painéis compostos por cinco lâminas de madeira de Araucaria angustifolia (Bert.) Ktze, sendo utilizadas as resinas uréia-formaldeído - UF e fenol-formaldeído - FF, com três repetições por tratamento. As seguintes formulações (em partes por peso) foram utilizadas: resina uréiaformaldeído -100 , extensor -50 , água -50 , catalisador -7 e, resina fenol-formaldeído -100 , extensor -18 , água -22 . Os resultados de resistência da linha de cola obtidos para os painéis produzidos tanto com a resina uréia-formaldeído, quanto com a resina fenol-formaldeído, apontaram para a viabilidade de uso do extensor a base de farinha de babaçu em substituição parcial ou total do extensor convencional a base de farinha de trigo na produção de painéis compensados multilaminados.

Palavras-chave: extensor; farinha de babaçu; compensado; Araucaria angustifolia.

\section{ABSTRACT}

This work aims at evaluating the potentiality of babaçu flour under differents percents $(0 \%, 50 \%$, $75 \%$, and $100 \%$ ) as alternative extensers to wheatmeal for plywood manufacturing. Third three panels with five veneers were produced using Araucaria angustifolia (Bert.) Ktze, with urea-formaldehyde - UF and phenol-formaldehyde - FF resins and being three panels per treatment. The following formulations (in parts per wheight) were used: UF resin $-100 \mathrm{x}$ extender $-50 \mathrm{x}$ water $-50 \mathrm{x}$ catalyst -7 and FF resin $-100 \mathrm{x}$ extender $-18 \mathrm{x}$ water -22 . The results of both glue line shear strength obtained for plywood manufactured with urea-formaldehyde and phenol-formaldehyde resins showed the feasibility of the use of babaçu flour as the extender in parcial or total substitution of wheat flour in the plywood manufactures.

Keywords: extender; babaçu flour; plywood; Araucaria angustifolia.

\section{INTRODUÇÃO}

Os painéis compensados podem ser produzidos em uma grande variedade de tipos e qualidade, dependendo da espécie de madeira e tipo de resina utilizada, podendo ser empregados nas mais variadas áreas, como indústria de construção civil, móveis, construção naval, construções para agricultura, construções industriais e em embalagens (FERREIRA, 2004). De acordo com Baldwin (1981) e Sellers Jr. (1985), a espécie de madeira utilizada na produção de um painel compensado responderá pelas características e propriedades tecnológicas do produto final, interferindo na colagem, estabilidade dimensional, resistência mecânica, etc.

Na produção de painéis de madeira, são utilizadas geralmente as resinas sintéticas uréia-formaldeído e fenol-formaldeído, uma vez que apresentam uma acelerada cura dinamizando o processo produtivo. No emprego de painéis para áreas exteriores, obtêm-se excelentes resultados com a resina à base de fenol, uma vez que os painéis produzidos são resistentes à umidade.

1. Engenheira Florestal, Msc., Professora Assistente do Departamento de Engenharia Agrícola, Faculdade de Engenharia Agrícola, Universidade Federal de Pelotas, Campus Universitário, s/n, CEP: 96010-900, Capão do Leão (RS). erika.ferreira@ufpel.edu.br

2. Engenheiro Florestal, Dr., Professor Associado do Departamento de Produtos Florestais, Instituto de Florestas, Universidade Federal Rural do Rio de Janeiro, CEP: 23890-000, Seropédica (RJ). edva@ufrrj.br

3. Engenheiro Florestal, Dr., Professor Titular do Departamento de Engenharia e Tecnologia Florestal, Setor de Ciências Agrárias, Universidade Federal do Paraná, CEP: 80210-170, Curitiba (PR). setsuo@ufpr.br

4. Engenheira Florestal, Msc., Professora Assistente do Curso de Engenharia Florestal, Campi São Gabriel, Universidade Federal do Pampa, Av. Antônio Trilha, 1847, CEP: 97300-000, São Gabriel (RS). silvianarosso@unipampa.edu.br

5. Engenheiro Florestal, Doutorando do Programa de Pós-Graduação em Engenharia Florestal, Setor de Ciências Agrárias, Universidade Federal do Paraná, CEP: 80210-170, Curitiba (PR). djeison1984@gmail.com

Recebido para publicação em 16/04/2008 e aceito em 14/08/2009. 
A formulação do adesivo com diferentes proporções de resina, extensor, água e catalisador deve ser otimizada em função do nível de qualidade exigida para as diversas aplicações (MARRA, 1992). As indústrias de compensados no Brasil utilizam como extensor a farinha de trigo, a qual, é um produto que além de ser quase que totalmente importada, é matéria-prima para indústria alimentícia. Em razão desse fato, estudos têm sido desenvolvidos na busca por materiais alternativos para a substituição do trigo como extensor na produção de compensados.

Moreira (1985) descreve materiais como farinhas de centeio, soja, milho, mandioca, sorgo, aveia, cevada, arroz, caroço de algodão, sangue de animais, batatas, entre outros, tendo alguns deles apresentado grande potencial de utilização. Em pesquisa desenvolvida por Iwakiri et al. (2000), foram avaliadas farinhas de mandioca, aveia, milho, arroz e soja, obtendo-se resultados satisfatórios para o uso de alguns desses extensores alternativos.

Segundo Marra (1992), o extensor é um material adicionado na mistura com resina e outros componentes da "batida de cola" e tem como função reduzir o custo final do adesivo, auxiliar no controle da viscosidade e nas funções de movimento do adesivo, desde a fase de espalhamento até a sua solidificação ou cura.

Este trabalho foi desenvolvido com o objetivo de avaliar a viabilidade de utilização da farinha de babaçu como extensor, em substituição parcial ou total a farinha de trigo, na produção de painéis compensados de uso interior e exterior.

\section{MATERIAL E MÉTODO}

Nesta pesquisa, foram utilizadas lâminas de Araucaria angustifolia (Bert.) Ktze, com espessura nominal de 2,0 mm, doadas pela empresa Hexion T.M. Para a colagem de lâminas foram utilizadas a resina uréia-formaldeído com viscosidade de $560 \mathrm{cP}, 53 \%$ de sólidos, $\mathrm{pH} 8,0$ e catalisador a base de sulfato de amônia e resina fenol-formaldeído com viscosidade de $740 \mathrm{cP}, 48 \%$ de sólidos, $\mathrm{pH}$ 11,4 e farinha de trigo e farinha de babaçu como extensores.

As lâminas foram secas a um teor de umidade em torno de $8 \%$ e, posteriormente, seccionadas em dimensões finais do painel de $40 \times 40 \mathrm{~cm}$. Os adesivos foram preparados de acordo com as seguintes formulações em partes por peso: resina uréia-formaldeído - 100, extensor - 50, água - 50 e catalisador -7 e resina fenol-formaldeído -100 , extensor -18 , água -22 . Foram produzidos painéis compostos por cinco lâminas com gramatura de $360 \mathrm{~g} / \mathrm{m}^{2}$ por linha dupla de colagem. Os ciclos de prensagem adotados foram: UF $=>$ temperatura $=110^{\circ} \mathrm{C}$, pressão específica $=10 \mathrm{kgf} / \mathrm{cm}^{2}$ e tempo de prensagem $=8$ minutos; $\mathrm{FF}=>$ temperatura $=140^{\circ} \mathrm{C}$, pressão específica $=10 \mathrm{kgf} / \mathrm{cm}^{2}$ e tempo de prensagem $=10$ minutos. Os tratamentos definidos para a pesquisa estão esquematizados na Tabela 1. Para cada tratamento foram produzidos três painéis, num total de 24 . Após a prensagem, os painéis foram esquadrejados e acondicionados em câmara de climatização à temperatura de $20 \pm 1{ }^{\circ} \mathrm{C}$ e umidade relativa de $65 \pm \%$, até atingir umidade de equilíbrio em torno de $12 \%$.

TABELA 1: Plano experimental utilizado para manufatura dos painéis compensados.

TABLE 1: Experimental plan for plywood manufactures.

\begin{tabular}{c|c}
\hline Tratamento & \multicolumn{1}{|c}{ Resina + Extensor } \\
\hline 01 & $\mathrm{UF}+100 \% \mathrm{FT}$ \\
02 & $\mathrm{UF}+50 \% \mathrm{FT} / 50 \% \mathrm{FB}$ \\
03 & $\mathrm{UF}+25 \% \mathrm{FT} / 75 \% \mathrm{FB}$ \\
04 & $\mathrm{UF}+0 \% \mathrm{FT} / 100 \% \mathrm{FB}$ \\
05 & $\mathrm{FF}+100 \% \mathrm{FT}$ \\
06 & $\mathrm{FF}+50 \% \mathrm{FT} / 50 \% \mathrm{FB}$ \\
07 & $\mathrm{FF}+25 \% \mathrm{FT} / 25 \% \mathrm{FB}$ \\
08 & $\mathrm{FF}+0 \% \mathrm{FT} / 100 \% \mathrm{FB}$ \\
\hline
\end{tabular}

Em que: UF = Uréia-Formaldeído; FT = Farinha de Trigo; FB = Farinha de Babaçu; FF = Fenol-Formaldeído.

De cada painel foram retirados vinte corpos de prova para ensaios de cisalhamento da linha de cola, sendo dez corpos de prova destinados ao teste seco (acondicionados) e dez para o teste úmido (resina UF) e dez para o teste de fervura (resina FF). Posteriormente foi determinada a percentagem de falha na madeira. Os ensaios foram realizados de acordo com os procedimentos descritos na norma Europeia EN $314-2$ 
(1993).

Para análise estatística dos resultados, utilizou-se o delineamento inteiramente casualizado, com a análise de variância e teste de Tukey a $95 \%$ de probabilidade.

\section{RESULTADOS E DISCUSSÃO}

Os valores médios de resistência da linha de cola ao esforço de cisalhamento e percentagem de falha na madeira para o teste a $12 \%$ de umidade e após imersão em água, de painéis compensados produzidos com resina uréia-formaldeído, estão apresentados na Tabela 2.

TABELA 2: Resultados dos ensaios de cisalhamento da linha de cola e percentagem de falha de compensados produzidos com resina uréia-formaldeído.

TABLE 2: Results of glue line shear and percentage of wood failure of plywood manufactured from ureaformaldehyde resin.

\begin{tabular}{l|c|c|c|c|c|c}
\hline \multirow{2}{*}{ Tratamento - Resina/Extensor } & \multicolumn{3}{|c|}{ Teste a 12\% de umidade } & \multicolumn{3}{|c}{ Após imersão em água } \\
\cline { 2 - 8 } & $\begin{array}{c}\text { RLC } \\
(\mathrm{MPa})\end{array}$ & $\begin{array}{c}\text { CV } \\
(\%)\end{array}$ & $\begin{array}{c}\text { Falha } \\
(\%)\end{array}$ & $\begin{array}{c}\text { RLC } \\
(\mathrm{MPa})\end{array}$ & $\begin{array}{c}\text { CV } \\
(\%)\end{array}$ & $\begin{array}{c}\text { Falha } \\
(\%)\end{array}$ \\
\hline T01 - Uréia-formaldeído/0\% FB & $1,45^{\mathrm{a}}$ & 21,70 & 13,83 & $0,83^{\mathrm{b}}$ & 14,04 & 2,67 \\
T02 - Uréia-formaldeído/50\% FB & $1,33^{\mathrm{a}}$ & 9,92 & 11,00 & $0,78^{\mathrm{b}}$ & 25,98 & 2,33 \\
T03 - Uréia-formaldeído/75\% FB & $1,13^{\mathrm{b}}$ & 16,37 & 8,33 & $0,81^{\mathrm{b}}$ & 39,33 & 1,67 \\
T04 - Uréia-formaldeído/100\% FB & $1,32^{\mathrm{a}}$ & 14,90 & 8,21 & $1,08^{\mathrm{a}}$ & 48,04 & 13,33 \\
\hline
\end{tabular}

Em que: Médias seguidas pela mesma letra, dentro de uma mesma coluna, não diferem estatisticamente entre si ao nível de 5\% de probabilidade pelo teste Tukey; RLC: resistência da linha de cola; CV: coeficiente de variação; FB: Farinha de Babaçu.

Os valores médios de resistência da linha de cola ao esforço de cisalhamento para os painéis produzidos com adesivo uréia-formaldeído variaram de 1,13 $\mathrm{MPa}(\mathrm{T} 03)$ a 1,45 $\mathrm{MPa}$ (T01) para o teste seco e de $0,78 \mathrm{MPa}$ (T02) a 1,08 MPa(T04) para o teste úmido.

Para o teste seco, pode se observar que, no tratamento 03 , com $75 \%$ de farinha de babaçu, houve uma redução estatisticamente significativa nos valores médios de resistência da linha de cola em comparação aos painéis testemunhas produzidos com $100 \%$ de farinha de trigo e dos demais tratamentos. A substituição parcial $(50 \%)$ ou total $(100 \%)$ da farinha de trigo pela farinha de babaçu não influenciou, de forma significativa, os valores médios de resistência da linha de cola. Com relação à percentagem de falhas na madeira, os valores obtidos ficaram bastante abaixo do esperado e mostra também uma tendência de redução destes com aumento na percentagem de substituições da farinha de trigo pela farinha de babaçu.

Com relação ao teste úmido, os painéis produzidos com 50 e $75 \%$ de farinha de babaçu em substituição à farinha de trigo apresentaram valores médios de resistência da linha de cola estatisticamente iguais em comparação aos painéis produzidos com $100 \%$ de farinha de trigo. A substituição de $100 \%$ de farinha de trigo com a farinha de babaçu resultou em painéis com valor médio de resistência da linha de cola estatisticamente superior em relação aos painéis testemunhas produzidos com $100 \%$ de farinha de trigo e demais tratamentos com 75 e $50 \%$ de substituições. A percentagem de falhas na madeira apresentou também para o teste úmido, tendências de redução com o aumento na percentagem de farinha de babaçu na mistura, com exceção do tratamento T04 cujos painéis foram produzidos com 100\% de farinha de babaçu.

Os resultados obtidos tanto para o teste seco quanto para o teste úmido apontam para a possibilidade de uso de farinha de babaçu como extensor alternativo na produção de painéis compensados com resina uréia-formaldeído, nas condições de uso intermediário. Cabe ressaltar ainda que, o valor médio de resistência da linha de cola no teste úmido obtido para os painéis produzidos com $100 \%$ de farinha de babaçu (T04) foi superior ao requisito mínimo de $1,0 \mathrm{MPa}$, independente da percentagem de falhas na madeira, conforme estabelecido pela norma Européia EN 314-2 (1993).

Em referência aos estudos realizados por outros autores, Moreira (1985) encontrou para painéis produzidos com lâminas de Araucaria angustifolia, resina uréia-formaldeído e extensores à base de farinhas de trigo, mandioca, milho, arroz, e batata, valores de resistência da linha de cola no teste úmido na faixa de 1,18 a $1,65 \mathrm{MPa}$.

Iwakiri et al. (2000), avaliando diferentes extensores para compensados ureicos produzidos com 
lâminas de Eucalyptus cloeziana, obtiveram para painéis produzidos com farinha de soja e de aveia, resultados de resistência da linha de cola no teste úmido de 1,46 MPa e 1,24 MPa respectivamente, sendo tais valores superiores em comparação aos painéis produzidos com a farinha de trigo como extensor cujo valor médio foi de 1,02 MPa.

Os valores médios de resistência da linha de cola ao esforço de cisalhamento e percentagem de falha na madeira para o teste a $12 \%$ de umidade e após fervura, de painéis compensados produzidos com resina fenol-formaldeído, estão apresentados na Tabela 3.

TABELA 3: Resultados dos ensaios de cisalhamento da linha de cola e percentagem de falha na madeira de compensados produzidos com resina fenol-formaldeído.

TABLE 3: Results of glue line shear and percentage of wood failure of plywood manufactured from phenol-formaldehyde resin.

\begin{tabular}{l|c|c|c|c|c|c}
\hline \multirow{2}{*}{ Tratamento - Resina/Extensor } & \multicolumn{2}{|c|}{ Teste a 12\% de umidade } & \multicolumn{3}{c}{ Após fervura } \\
\cline { 2 - 8 } & $\begin{array}{c}\text { RLC } \\
(\mathrm{MPa})\end{array}$ & $\begin{array}{c}\text { CV } \\
(\%)\end{array}$ & $\begin{array}{c}\text { \% } \\
\text { Falha }\end{array}$ & $\begin{array}{c}\text { RLC } \\
(\mathrm{MPa})\end{array}$ & $\begin{array}{c}\text { CV } \\
(\%)\end{array}$ & $\begin{array}{c}\% \\
\text { Falha }\end{array}$ \\
\hline T05 - Fenol-formaldeído/0\% FB & $2,58^{\mathrm{a}}$ & 21,09 & 59,33 & $1,59^{\mathrm{a}}$ & 16,11 & 27,00 \\
T06 - Fenol -formaldeído/50\% FB & $1,97^{\mathrm{c}}$ & 11,75 & 25,67 & $1,13^{\mathrm{b}}$ & 15,16 & 10,00 \\
T07 - Fenol -formaldeído/75\% FB & $2,27^{\mathrm{b}}$ & 11,00 & 56,67 & $1,48^{\mathrm{a}}$ & 11,99 & 25,52 \\
T08 - Fenol -formaldeído/100\%FB & $2,35^{\mathrm{b}}$ & 12,23 & 30,00 & $1,27^{\mathrm{b}}$ & 16,99 & 35,00 \\
\hline
\end{tabular}

Em que: Médias seguidas pela mesma letra, dentro de uma mesma coluna, não diferem estatisticamente entre si ao nível de $5 \%$ de probabilidade pelo teste Tukey; RLC: resistência da linha de cola; CV: coeficiente de variação; FB = Farinha de Babaçu.

Os valores médios de resistência da linha de cola ao esforço de cisalhamento para os painéis produzidos com adesivo fenol-formaldeído variaram de 1,97 MPa(T06) a 2,58 $\mathrm{MPa}(\mathrm{T} 05)$ para o teste seco e de 1,13 MPa(T06) a 1,59 $\mathrm{MPa}(\mathrm{T} 05)$ para o teste de fervura.

Os painéis produzidos com substituição parcial e total da farinha de trigo pela farinha de babaçu, resultaram em valores médios de resistência da linha de cola no teste seco, estatisticamente inferior em relação aos painéis testemunhas produzidos com $100 \%$ de farinha de trigo como extensor (T05). Entretanto, em termos de médias absolutas, os painéis produzidos com 75 e $100 \%$ de farinha de babaçu, apresentaram valores médios bastante próximos da média obtida para os painéis testemunhas (T05).

Para o teste de fervura, as médias obtidas para os painéis produzidos com $75 \%$ de farinha de babaçu (T07) e os painéis testemunhas (T05) não diferiram estatisticamente entre si. Já, os painéis correspondentes aos tratamentos T06 e T08, com 50 e 100\% de babaçu, apresentaram médias de resistência da linha de cola estatisticamente inferiores em comparação aos painéis testemunhas (T05).

Com relação à percentagem de falhas na madeira no teste seco, os maiores valores foram obtidos para os painéis testemunhas (T05) e tratamento T07, com 59,33 e 56,67\% respectivamente. Para o teste de fervura, verificou-se uma tendência de aumento na percentagem de falhas na madeira com o aumento na proporção de farinha de babaçu de 50, 75 e 100\% na mistura da batida de cola.

Os resultados obtidos no teste de fervura apontam para a viabilidade de uso de farinha de babaçu para produção de painéis compensados com resina fenol-formaldeído, tendo em vista que os valores médios de resistência da linha de cola obtidos para todos os tratamentos com diferentes proporções de mistura, atendem ao requisito mínimo da norma Européia EN 314-1 (1993) de 1,0 MPa.

\section{CONCLUSÕES}

Com base nos resultados obtidos nesta pesquisa, as seguintes conclusões podem ser apresentadas:

Os painéis produzidos com resina uréia-formaldeído e percentuais de substituição de farinha de trigo por 50 e $100 \%$ de farinha de babaçu foram os que apresentaram melhores resultados de resistência da linha de cola no teste seco, sendo estatisticamente iguais em comparação aos painéis testemunhas, produzidos com $100 \%$ de farinha de trigo como extensor;

Com relação ao teste úmido, todas as percentagens de substituição do extensor convencional (farinha de trigo) pelo extensor alternativo (farinha de babaçu), resultaram em painéis com valores médios de 
resistência da linha de cola iguais, para tratamentos T02 (50\%) e T03 (75\%), ou superior, para tratamento T04 (100\%), em comparação aos painéis produzidos com 100\% (T01) de farinha de trigo.

Para os painéis produzidos com resina fenol-formaldeído, a substituição parcial e total do extensor convencional pela farinha de babaçu resultou na redução da resistência da linha de cola no teste seco; Já, nos testes de fervura, os painéis produzidos com percentagem de substituição de $75 \%$ da farinha de trigo pela farinha de babaçu, resultaram em resistência da linha de cola estatisticamente igual em relação aos painéis produzidos com farinha de trigo.

Os resultados obtidos para os painéis produzidos tanto com a resina uréia-formaldeído, quanto com a resina fenol-formaldeído apontam para a viabilidade de uso do extensor de babaçu em substituição parcial ou total da farinha de trigo na produção de painéis compensados multilaminados.

\section{AGRADECIMENTOS}

Os autores deste trabalho expressam seus agradecimentos à empresa Hexion T. M. respectivamente, pela doação das lâminas de araucária e resinas utilizadas neste trabalho. Ao Laboratório de Tecnologia da Madeira e a Marcenaria da UFPR pela disponibilidade de confecção dos corpos de prova e realização dos ensaios.

\section{REFERÊNCIAS BIBLIOGRÁFICAS}

BALDWIN, R. F. Plywood manufacturing practices. San Francisco: Miller Freeman, 1981. 326 p.

EUROPEAN COMMITTEE FOR STANDARDIZATION. Plywood- Bonding Quality: part 1 - test methods. EN $314-1: 1993$.

EUROPEAN COMMITTEE FOR STANDARDIZATION. Plywood - Bonding Quality: part 2 - requirements. EN $314-2: 1993$.

FERREIRA, E. S. Utilização dos polifenóis da casca de pinus para produção de adesivos para compensados. 2004. 79 f. Dissertação (Mestrado em Ciências Ambientais e Florestais) - Universidade Federal Rural do Rio de Janeiro, Seropédica.

IWAKIRI, S. et al. Utilização de extensores alternativos na produção de compensados multilaminados. Ciência Florestal, Santa Maria, v.10, n. 1, p. 77-83, mar./abr. 2000.

MARRA, A. A. Technology of Wood Bonding. New York: Van Nostrand Reinhold, 1992. 453 p.

MOREIRA, W. S. Extensores alternativos para produção de compensados com resina uréia-formaldeído. 1985.

81 f. Dissertação (Mestrado em Engenharia Florestal) - Universidade Federal do Paraná, Curitiba.

SELLERS JÚNIOR, T. Plywood and adhesive technology. New York: Marcel Dekker, Inc. 1985. 661 p. 